\title{
Pandemi sürecinde sözsüz iletişim dili: Yeni emoji tasarımları
}

\section{Eda SEZERER ALBAYRAK1}

APA: Sezerer Albayrak, E. (2020). Pandemi sürecinde sözsüz iletişim dili: Yeni emoji tasarımları. RumeliDE Dil ve Edebiyat Araşttrmaları Dergisi, (20), 64-76. DOI: 10.29000/rumelide.791090.

\section{$\ddot{\mathbf{O} z}$}

Akıllı telefonların ve bilgisayarların hızlı bir şekilde yaygınlaştı̆̆ı günümüzde bireylerin duygu ve düşüncelerini birbirlerine aktarmada önemli rol oynayan sözsüz iletişim araçlarından biri olan emojiler günlük hayatın vazgeçilmez parçaları haline gelmişlerdir. Çünkü, emojiler sembollerden oluşarak bir anlam meydana getirdikleri için bireyler arasında bir iletişimi sağlamaktadırlar. Bu iletişim şu anda ulusal ve uluslararası alanda yeni bir dil olarak kullanılmakta ve evrensel bir hale gelmiş durumdadır. Bu doğrultuda çalışmanın amacı, 2019 Aralık ayında Çin'de başlayıp tüm dünya da halen etkisini sürdürmekte olan koronavirüsün etkilerini anlatan emojiler tasarlamaktır. Çalışma nitel bir araştırmadır. Tasarlanan emojilerin temalarını açıklamak ve düzenlemek için içerik analizi yöntemi kullanılmıştır. Çalışmada giriş, kavramsal çerçeve, bulgular, yorum, sonuç ve öneriler bölümleri yer almaktadır.

Anahtar kelimeler: Sözsüz iletişim, emoji, Koronavirüs, Covid 19, tasarım

\section{Language of nonverbal communication in the pandemic process: New emoji designs}

\begin{abstract}
Emoji's have become indispensable parts of everyday life being one of the tools of nonverbal communication that plays an important role in conveying individuals' feelings and thoughts about each other, Emojis are formed by symbols and become meaninful and they provide a communication between individuals. This communication is now being used nationally and internationally as a new language and has become universal. The aim of the study is to design emojis describing the effects of the coronavirus, which had started in China in December 2019 and is still affecting the whole world. The study is a qualitative research. A method of content analysis has been used to explain and edit the themes of the designed emojis. Introduction, conceptual framework, findings, comments, conclusions and recommendations are included in the study.
\end{abstract}

Keywords: Nonverbal communication, emoji, Coronavirus, Covid 19, design

\section{Giriş}

İletişim sözcüğü İngilizce ve Fransızca'da aynı şekilde yazılan okunurken ayrı olan "communication" sözcüğünden türemiştir. İletişim sözcüğü eskiden sadece haberleşme kavramının karşlığı olarak kullanılmaktaydı. Günümüzde ise bireyler arasında karşılıklı olarak bir alışverişi ifade etmektedir (Zillığlu, 1996:3). Türk dil kurumuna göre ise iletişim, "Duygu, düşünce veya bilgilerin akla gelebilecek

Dr. Öğr. Üyesi, KTO Karatay Üniversitesi, Sosyal ve Beșeri Bilimler Fakültesi, İletișim ve Tasarımı Bölümü (Konya, Türkiye) eda.albayrak27@gmail.com, ORCID ID: 00o0-0002-2195-0772 [Makale kayit tarihi: 10.07.2020-kabul tarihi: 20.09.2020; DOI: 10.29000/rumelide.791090] 
her türlü yolla başkalarına aktarılması, bildirişim, haberleşme, komünikasyon.” olarak yapılmıştır (http://www.tdk.gov.tr/).

İletişim kavramı, birçok kişi tarafından farklı işlevleri ön plana çıkarılarak tanımlanmaktadır. Ancak, bu tanımlamaları içeren geniş kapsamlı bir tanım yapılması gerekirse iletişim; "kişiler arasında kurulan ve duygu, düşünce, niyetlerin aktarılmasını sağlayan etkileşim; belirli bir düşünce, mesaj ya da bilinç içeriğinin, söz, konuşma ya da bedensel tavır şeklinde çeşitli araçlarla bir insandan bir başkasına aktarılması" (Gürgen, 1997:3) sürecidir.

Jestler sözsüz iletişim dendiğinde akla ilk gelenlerdendir. Jestlerin doğru anlamlandırılması, kültür gibi jestlerin kullanıldığı kontekst ile de ilişkilidir ve sosyal yaşamda büyük yer kaplayan sözsüz iletişimin "kimlik tanımlama", "güç ve statü iletişimi”, "söz tanımlama", "vurgulama", "farklılaştırma", "dikkat çekme”, "sözün yerini alma”, “düzenleme”, "pekiştirme” gibi işlevleri vardır. Sözsüz iletişim duygusal işlevler üstlenmiştir ve duygunun surat ifadesi ile yansıtılmasında etkilidir (Kaya, 2017: 575).

Buradan hareketle iletişimin çeşitli parçalardan oluşan bir sistem olduğu söylenebilir. Bu sistem içindeki parçalar özellikle bedensel tavır parçasındaki konuşma esnasında kullanılan jest ve mimikler kısıtlı zamanlarda bireyler tarafindan kullanılan sembol ve ikonlar olmuştur.

İkon ve semboller için göstergeler önemlidir. Göstergeler, toplumsal yaşam ve ilişkilerde belirli anlamlara sahiptirler ve pek çok şey hakkında bilgi, fikir verirler. Çağımızda düşündüğümüz şeyleri anlık mesaja çevirebilmekte ve mesajımızı hızla iletebilmekteyiz. Geri bildirim sürecinin hız kazandığı yeni iletişim çağında insan, yazı yazmaya ayırdığı zamanı azaltmanın peşine düşmüş ve bu amaçla türlü göstergelere başvurmaya başlamıştır (Torun, 2018). Dilsel göstergelerin olduğu gibi ikon, ve sembol gibi dil dışı göstergeler de birer anlam taşıyıcısıdırlar. Anlam taşıyıcısı oldukları için bir iletişim meydana getirebilirler. Teknolojinin gelişmesiyle beraber yeni iletişim araçları artmaktadır. Bu araçlarla yapılan ve anlam taşıyan her tür, gösterge dil olarak tanımlanabilir. Sosyal medya ağlarının her birinin kendi içinde dili ve söz varlığı oluşmuştur (Çeken vd., 2017:92). Bu sebepten şimdilerde teknolojik ve rutin alanda bir takım yeni göstergelerden söz edilmektedir. Emojiler bu yeni göstergelerden en öne çıanlardır.

Emoji terimi Japonca 絵 $(\mathrm{e} \cong \mathrm{resim})$ 文 $(\mathrm{mo} \cong$ yazmak) 字 $(\mathrm{ji} \cong$ karakter) kelimelerinden gelmektedir. (Davis ve Edberg, 2016). Emoji, duyguları, nesneleri, kavramları ifade etmek için kullanılan görsel sunumlardır. Bilgisayar aracılı̆̆ıyla iletişimde sözlü olmayan ipuçları yerine geçen emojiler internet iletişiminde yaygın olarak kullanılmaktadır (Dimson, 2015).

İnsanlık tarihi boyunca, ölümcül bulaşıcı hastalıkların toplumsal yaşamı tehdit eden en korkutucu felaketler olduğu aşikârdır. Doğal afetler ve savaşlar sadece belli coğrafik bölgelerle sınırlı kalırken, bulaşıcı hastalıklar tüm insanlığı etkilemiş ve insanın olduğu her yerde etkisini büyük ölçüde göstermiştir. Bu etki sadece insanlığı değil aynı zamanda bütün iletişim çeşitlerini de etkilemiştir. İnternette sözsüz iletişimin yerine yaygın olarak kullanılan emojiler bulunduğumuz yılda ortaya çıan koronovirüs - koronavirüs ailesinden, zarfl tek zincirli, pozitif polariteli, bir RNA virüsü olan SARS$\mathrm{CoV}$-2 şu an için tüm dünyada pandemiye sebep olmuştur. SARS-CoV-2, Koronavirüs ailesinden, zoonotik yeni bir virüstür. İlk kez 7 Ocak 2020'de tanımlanan bu yeni virüs virulansı çok hızh olması sebebi ile küresel ölçekte hızla yayılmasının ardından Dünya Sağlık Örgütü DSÖ tarafindan COVID19 olarak adlandırıldı ve yaşanan bu salgın pandemi olarak kabul edildi. Hastahğın ilk tanısı oldukça karmaşık bir süreç ile konuldu. Tedavi etmenin ve yayılımını önlemenin yanında hızh bir şekilde aşı 
çalş̧maları başlamıştır. Önleyici bir aşı ya da kesin tedavi edecek bir ilacı henüz bulunamamıştır (Demiray ve Çeviker, 2020:38). - salgınından etkilenmiştir.

Dünya üzerindeki neredeyse her ülkede görülen ve 95 binin üzerinde kişinin hayatına mal olan corona virüs (COVID-19) ekonomide de ciddi etkiler yaratıyor. Pek çok şirket salgın sonrası operasyonlarını erteleme kararı aldı. Bu şirketler kervanına akıllı cihazlarımızda kullandığımız emoji’lerin üreticisi The Unicode Consortium da katıldı. The Verge'de yer alan habere göre The Unicode Consortium corona virüs salgını nedeniyle yeni emoji'lerin akıllı cihazlara geleceği tarihi erteleme kararı aldı. Aynı habere göre, şirket önümüzdeki yll kullanıma girmesi planlanan yeni emoji'lerin çıkış tarihini bir yıl erteledi. Başka bir deyişle salgın nedeniyle akıllı cihazlara gelecek yeni emoji’ler 2022 yılında kullanıma sunulacak (www.ntv.com.tr).

Çalışmanın amacı, toplumu etkileyen bu pandemi sürecinde kullanılmak üzere koronavirüsün etkilerini anlatan emojiler tasarlamaktır. Bu araştırmada nitel araştırma yöntemi uygulanmaktadır. Model olarak tarama modelinden yararlanılmıştır. Alanyazına bakıldı̆̆ında emoji ile ilgili çok fazla çalışma bulunmamaktadır. Hali hazırda yapılmış olan çalışmalarda da genellikle anket ve koreloasyon analizi gibi teknikler uygulanmıştır. Bu bağlamda çalışma alanyazında ilk olması açısından önemlidir. Çünkü, küresel olarak yaşanan salgına ait tüm dünya insanın her gün kullandığı sözsüz iletişimin önemli bir parametresi olan emojilere katkı sağlayacaktır. Günümüzde günlük yazışmalarda kullanılan emojilerde koronovirüs ile alakalı tasarlanan emojiler yok denecek kadar azdır.

\section{Kavramsal çerçeve}

\section{Emojinin gelişme süreci}

Emoji, ilk önce ifadelere dönüşen gülücük işaretiyle (smiley) (-) ortaya çıkmış ve ardından son yıllarda bu gülücük işaretini emoji ve çıkartmalar takip etmiştir. Gülücük işareti ilk olarak 1960'larda kendisini göstermiş ve ilk ifade sembolleri olarak kabul edilmiştir. Smiley, gözler için iki nokta ve düğmeler, broşlar ve tişörtler üzerine basılmış geniş bir sırıtış ile sarı bir yüzdür. 1980'lerin başında, bu sembol yaygınlaşmış ve Batı popüler kültürünün kalıcı bir özelliği olarak ortaya çıkmıştır. (Stark ve Crawford, 2015).

İfadeler 1872 'de tanıtılmış olup belirli bir ifadeyle bir yüzün temsilini oluşturmak için standart bir bilgisayar klavyesinden sıradan noktalama işaretleri kullanılarak ortaya çıkarılmış ve cümle sonlarında sıklıkla kullanılan paralinguistik bir unsur haline gelmiştir (Sakai, 2013). Emoji'nin kullanılmasından önce, Anlık Mesajlaşma (IM=instant messaging) kullanıcıları genellikle bu noktalama işaretleri ile ortaya çıkarılan ifadeleri kullanmaktaydı. Yüz yüze iletişimde sözel olmayan ipuçları gibi bu ifadeler de belirsiz bağlamlardaki niyetleri netleştirmeye yardımcı olabilmekte, ve iletişimin verimliliğini artırmaktadır. Bununla birlikte onları alan kişilerin gönderenin duygularını, tutumunu ve dikkat düzeyini doğru bir şekilde anlamalarına yardımcı olabilmektedir (Lo, 2008). Ayrıca keyifli bir iletişim sağlamak, etkileşimi teşvik etmek ve topluluk kimliğini göstermek gibi etkileri vardır. (Cho, 2016). Uygulamada cinsiyet ve kültürel farklılıklar ifade kullanımları için farklı tercihler ortaya çıarmaktadır. İfadelerin, örneğin duygusal izleme gibi alanlarda gerçek hayata uygulanabileceği de öne sürülmüştür. Bunun dışında psikolojik testler ve tasarım işaretlerinde de kullanılabilmektedir. (Sodikin, 2018).

Japon yaratıcısı Shigetaka Kurita (盖田粠㗬) tarafından hazırlanan ilk emoji seti 1999 yılında piyasaya sürülmüştür. "Emoji" Japonca bir kelimenin başka bir alfabeye çevirilmiş halidir: 
絵 (e=betimlemek,resim) 文 (mo=yazmak) 字 (ji=karakter). Bunlar, yalnızca yüz ifadelerini, soyut kavramları ve duyguları değil, aynı zamanda hayvanları, bitkileri, aktiviteleri, hareketleri/vücut parçalarını ve nesneleri temsil edebilen önceden tanımlanmış isimlere ve kodlara (Unicode $=$ evrensel nitelikte kodlar) sahip grafik sembollerdir (Rodrigues ve diğerleri, 2017). Emojilerin yüz yüze iletişime benzer sinirsel tepkileri gösterebilen niteliklere sahip olması iletişim sırasında ekstra duygusal veya bağlamsal anlam ekleyebilmesini, mesajın alıcılara çekiciliğini artırabilmesini, ton ayarlamasını sağlamasının yanı sıra ayrıca konuşma sırasında kullanıcılara yardımcı olmakta ve kişilerarası ilişkileri yönetmede ve sürdürmede rol oynamaktadır. Emojiler görsel bir dil olarak kullanılmakta olduğundan Facebook, Instagram ve Twitter gibi İngilizce ağırlıklı sosyal medya uygulamalarını kullanmak için İngilizce konuşmakta olmayan ulusların sosyal düzeyde iletişim kurmasını kolaylaştırmaktadırlar. (Boothe ve Wickstrom, 2017). Emoji, anlık mesajlaşma, e-posta, Sosyal A ̆̆ ve diğer birçok CMC (Computer-mediated communication = Bilgisayar Aracılı̆̆ıla İletişim) formunda yaygın olarak kullanılmaktadır. Belirtildiği gibi, emoji, bilginin arkasındaki niyetleri ve duyguları ifade etmek için bilgisayar aracılı̆̆ıyla iletişimde sözel olmayan ipuçlarına olan ihtiyacı karşılamaktadır (Dresner ve Herring, 2010).

Son yıllarda, bilgi aktarımının yorumlanabilirliği ve anlamın daha iyi ifade edilebilmesi için çıkartmalar ortaya çıkmışıır. Çıkartmalar, stratejik ve dinamik olarak kullanıcıların duygularını, fikirlerini ve niyetlerini ifade etmelerine ve iletişimde akıcılı̆̆a ulaşmalarında en iyi yolunu seçmelerine yardımcı olabilmektedir. (Lim, 2015). Aynı zamanda, çıartmalar, kendini sunma, izlenim yönetimi, sosyal varoluşun kurulması ve sosyal statünün korunması gibi stratejik motifler için kullanılabilmektedir. Ayrıca, karşınızdaki kişiye metin ve çıkartma kombinasyonu ile cevap vermek, yakınlı̆̆ınızı artırmak açısından da önem taşıyabilmektedir. (Wang, 2016).

Smiley (gülen yüz işareti), ifadeler, emoji ve çıkartmalar form ve içerik bakımından farklılık göstermektedir ve kullanıcılar tarafından farklı dönemlerde tercih edilmiştir. Reklamlarda ve ürün ambalajında sıklıkla kullanılan "Smiley", olumlu ruh hallerine teşvik edebilir ve moralleri artırabilir. (Stark ve Crawford, 2015). Bir dizi karaktere sahip olan emoji, ifadeler ve çıkartmaların aksine, smiley iletişimde nadiren kullanılan tek bir semboldür. Smiley ve kullanılmakta olan diğer ifadeler noktalama işaretleri çeşitli kombinasyonları ile yüz ifadeleri ortaya çıkarmakta olup mevcut ve bilgisayar aracılığıyla iletişimde kullanılabilmektedir (Ganster ve diğerleri, 2012). Emoji, noktalama işaretleri ile oluşturulan ifadelerin gelişmiş bir versiyonu olarak kabul edilmiştir. Ayrıca içerik zenginliği, giriş hızı ve ifade gücü açısından ifadelerden daha üstündür. Her ikisi de yardımcı iletişim aracı olarak kullanılmakta olduğundan, emoji ve ifadeler benzer mesajlar için tamamlayıcı işleve sahiptir. Ancak emoji'nin ortaya çıkışının, ifadelerin durumunu belirli bir ölçüde etkilediği kanıtlanmıştır. İfadeler ile karşılaştırıldığında, kullanıcılar emojiyi daha sık kullanmaktadırlar. (Prada ve diğerleri, 2018). Çıkartmalar ise son zamanlarda ortaya çıkmıştır. Statik ve animasyonlu formlarla olup daha büyüktür, eklemeler veya çıkarmalar yapılabilir (emojiler düzenlenemeyen formdaki evrensel kodlara dayanmaktadır).

\section{Emoji kullanımı}

Bilgisayar aracılığıyla iletişimde sözlü olmayan ipuçları yerine geçen emojiler internet iletişiminde yaygın olarak kullanılmaktadır. Mart 2019 itibariyle günlük olarak kullanılan bu evrensel kodlardan 3.019 emoji bulunmakta olup Instagram'da (Dimson, 2015) tüm metin mesajlarının neredeyse yarısında ve Facebook üzerinde toplamda 5 milyar emoji kullanılmaktadır. 2015’te, şeklindeki emoji 
emojilerin sanal iletişimdeki rolünü göstererek Oxford İngilizce Sözlüğü tarafından yılın sözcüğü seçilmiştir. Duyguları belirtmek için kullanılan ifadelere sadelik getirerek ifade edilmesinde kolaylık sağlıyor olması kullanıcıları emoji kullanmaya çeken ana motivasyonlardandır. Özellikle, emoji kullanıcıların kendilerini ifade etmelerine, ruh hallerini rahatlıkla yansıtmalarına yardımcı olmakta ve kendilerini daha iyi ifade etmelerini sağlamaktadır (Kaye ve diğerleri, 2016). Bağlamsallaştırma ipuçları olarak görev yapmakta olan, emojiler etkileşimi teşvik etmek için iletişimde ayrıca, duygusal bağların oluşturulması, söylemlerdeki belirsizliğinin azaltılması, bağlam uygunluğunun arttırılması ve konuşma eylemlerini yoğunlaştırmak veya zayıflatmak) maksatlı kullanılmaktadır (Sampietro, 2019).

\section{Emojinin İşlevleri}

Bilgisayar aracılı̆̆ ile iletişimde önemli bir görsel sembol olan emoji, insanlar, hayvanlar, yiyecekler, aktiviteler de dahil olmak üzere çeşitli içerikleri ifade edebilmektedir. Emoji, emojinin anlamsal işlevi olan anlamları iletmek için hem bağımsız bir dil hem de sözsüz bir işaret olarak kullanılabilmektedir. Buna ek olarak, emoji duygusal işlevlere de sahiptir.

\subsection{Emojinin Duygusal İşlevleri}

Emojiler zengin duygusal anlamlara sahip sözel olmayan ipuçları oldukları için, internette etkileşim ve duygusal iletişim için önemli bir araçtırlar.

Emoji duyguları ifade edebilir ya da daha yoğun şekilde ifade edilmesini sağlayabilmektedir. Jaeger ve Ares, 33 yüz emojisini analiz etmiş ve çoğu emojinin bir veya daha fazla duyguyu ifade edebileceğini ortaya çıarmıştır. Emoji'nin içermekte olduğu zengin duygusal anlamlar, duyguları analiz eden ve duygusal emoji ifadelerini geliştiren araştırmacılar için emojileri üzerinde çalışılacak önemli bir alan haline getirmektedir (Jaeger ve Ares, 2017). Petra ve diğerleri, emojileri duygusal dağılımlarına göre pozitif, negatif ve nötr olarak ayırmış ve çoğu emojinin pozitif olduğunu ancak ironi veya hiciv ifade edebilen bazı emojiler de bulunduğunu öne sürmüştür. (Vanin ve diğerleri, 2013).

Zengin duygusal anlamları nedeniyle, emoji genellikle sanal iletişimde duyguları ifade etmek için kullanılmaktadır. Genel olarak, kullanıcılar olumlu mesajlarda daha fazla emoji kullanma eğilimi varken bunları üzgün veya öfkeli mesajlarda daha az kullanma eğilimindedir. (Cheng, 2017). Farklı emojiler, insanların dikkatini ve tepkilerini farklı şekillerde etkilemektedir. Hem yüz hem de yüz dışı emojilerle duygular ifade edilebilse de, bireyler arası iletişimde yüz emojisi yüz dışı emojilerden daha etkilidir. Yüz dışı emojiler kullanmak olumlu duyguları tetikleyebilmekte, özellikle de neşe getirebilmektedir, ancak mesajın değerini değiştirmemektedir. Farklı emoji kombinasyonları da duygusal ifadede ince farklllıklara sahiptir, örneğin López ve Cap, kurbağa emojisi veya sıcak içecek emojisini diğer emojilerle birleştirirken, ince ama gözlemlenebilir duygusal değişiklikler olabileceğini ortaya çıkarmıştır (Hjartstrom ve diğerleri, 2019).

\subsection{Emoji'nin anlamsal işlevi}

Duyguları ifade etmenin yanı sıra, emoji iletişimde semantik anlamları iletmek için de kullanılır. Emojiler bilgisayar aracıllğı ile iletişim mesajların genel anlamların gösterebilmek, ifade edilmeye çalışılan duygu ve durumların daha açık şekilde anlaşılmasına yardımcı olabilmek için sözsüz ipuçlarının rolünü oynayabilmektedirler. Emoji'nin bağımsız bir dil haline gelip gelemeyeceği konusunda çok fazla tartışma olmaktadır. Buna ek olarak, emoji semantiğinin çeşitliliği ve benzerliği 
nedeniyle, bilgisayar alanındaki birçok araştırmacı emoji'nin kelime anlam ayrımı görevine dikkat etmektedir (Na'aman ve diğerleri, 2017).

Bazı araştırmalar emoji'nin bağımsız bir dil oluşturduğunu göstermektedir. Anlamsal bir işleve ve görsel retorik işleve sahiptirler ve anlamlardan bağımsız olarak bir ifade etme yöntemi olarak kullanılabilirler ve farklı emojilerin birleşimi yoluyla daha ince semantiği ifade edebilirler. Emoji'nin anlamı belirli bağlamlara göre değişmektedir. Anlambilim çeşitliliği ve yorumlama esnekliği, bunları kullanırken belirsizliğe yol açabilmektedir. Bu nedenle, birçok araştırma emojinin kelime anlamında belirsizliği giderme görevi üzerinde durmaktadır (Jaeger ve diğerleri, 2019).

\section{Koronavirus (Covid 19)}

Koronavirüsler, soğuk algınlığından solunum yetmezliğine kadar ciddi hastalıklara sebep olan bir virüs ailesi olarak bilinmektedir (Til, 2020:2). Koronavirüsü ilk olarak Çin'in Hubei eyaletinde Wuhan şehrinde tespit edilmiştir, kaynağı kesin olarak bilinmemekle birlikte Hunan Deniz Ürünleri Toptan Satış Pazarındaki yasadışı satılan vahşi hayvanlardan kaynaklandığı tahmin edilmektedir (Til, 2020:3). Sağlık Bakanlığının yayınladığı bilgiye göre (2020); "Yeni Koronavirüs Hastalığı (COVID-19), ilk olarak Çin’in Vuhan Eyaleti’nde Aralık ayının sonlarında solunum yolu belirtileri (ateş, öksürük, nefes darlığı) gelişen bir grup hastada yapılan araştırmalar sonucunda 13 Ocak 2020'de tanımlanan bir virüstür. Koronavirüsler, hayvanlarda veya insanlarda hastalığa neden olabilecek büyük bir virüs ailesidir. İnsanlarda, birkaç koronavirüsün soğuk algınlığından Orta Doğu Solunum Sendromu (MERS) ve Şiddetli Akut Solunum Sendromu (SARS) gibi daha şiddetli hastalıklara kadar solunum yolu enfeksiyonlarına neden olduğu bilinmektedir. Yeni Koronavirüs Hastalığına SAR-CoV-2 virüsü neden olur.” (https://covid19bilgi.saglik.gov.tr/)

Korona virüsünün şiddeti ve etkileri bulaştı̆̆ kişilerin sağlığına, yaşına bağlı olarak farklılık göstermektedir. Yine korona virüsünün aktif bir şekilde var olması bulunduğu ortam koşullarına göre da değişmektedir. Bireyde ki hastalık belirtileri minimum 2, maksimum 14 gün aralığında değişmektedir. Hastalı̆̆ın bulaştığı kişilerde yüksek ateş, öksürük ve solunum sıkıntısı gibi belirtiler görülmektedir. Korona virüsüne yakalanan kişilerin bu belirtiler ile birlikte hafif/orta şiddette bir hastalık süreci geçirmektedirler. Fakat kronik rahatsızlığı olan ve yaşlı kişilerde daha ağır şiddetle kendini göstermekte hatta ölüme sebep olmaktadır (Til, 2020:3).

COVID -19 Teşhis bireyin solunum semptomlarında özel testler ile koyulur. Sonucun şüphe varlında tedavi planlaması akciğer grafiği ve dijital ortamda tomografi gibi görüntüleme yöntemi kullanılmaktadır. Tedavi olarak destekleyici ve ampirik bir yöntem uygulanmaktadır. Salgın için henüz bir tedavi ya da bir aşısı yoktur. Tedavi süreci için bilimsel araştırmalar devam etmektedir. Bireylerin temasının aza indirgenmesi, kesin tanı konmuş veya şüpheli vakaların izolasyonu bulaşıcılıktan korumak adına bireyin kendisini koruyucu ekipmanlar ile izole etmesi salgın ile edilen mücadelede büyük bir önem taşımaktadır (Dikmen, Kına, Özkan \& İlhan, 2020:30).

Bu bağlamda teşhis koyulmuş bireylerin izole edilmesi büyük önem taşımaktadır. Özel yaşam alanları dahil olmak üzere birey kendinin ve yaşam alanını paylaştığı aile bireylerinin sağlığı bakımından sosyal mesafeyi koruyup ortak kullanım alanlarını sınırlamalıdır. Hasta yakınlarının bu süreçte kendilerini koruma ekipmanları dışında normal bir bireyden daha fazla izole edip dikkat etmesi gerekmektedir. (Özdemir ve Pala, 2020,s.10). İzole durumları göz ardı edilmeden, teşhis konulmuş hastalar evlerinde tek kişilik bir odada doktor tedavisine uygun ortam ile kendilerini izole etmelidir. Kritik olan yani 
belirtileri yüksek oranda gösteren ve nefes alırken zorlanma yaşayan bireyler en kısa sürede yoğun bakım ünitelerine götürülmelidir. Bu evrede hastalar entübe edilmektedir. (Ayan ve Kıraç, 2020:2).

\section{Araştırmanın yöntemi}

Bu araştırmada 2019 Aralık ayında Çin'de başlayıp tüm dünya da halen etkisini sürdürmekte olan koronavirüsün etkilerini anlatan emojiler tasarlamak amacıyla içerik analizi yöntemi kullanılmıştır. Çalışma nitel bir araştırmadır. İçerik analizi sözel, yazılı ve diğer materyallerin nesnel ve sistematik bir şekilde incelenmesine olanak tanıyan bilimsel bir yaklaşımdır (Tavşancılve Aslan, 2001). Emojiler, bir vakıf üniversitesinin İletişim ve Tasarımı bölümünde okuyan öğrenciler tarafından tasarlanmıştır. Katılımcılar gönüllülük esas alınarak belirlenmiş̧tir. Her bir katılımcıya "Bilgilendirilmiş Gönüllü Onam Formu" verilmiş olup, çalışma sırasında ve sonrasında isimlerinin ve diğer kişisel verilerinin gizli kalacağı, hiçbir dijital ortamda kaydedilmeyeceği ve paylaşılmayacağı belirtilmiştir. Bu formu, tüm katılımcılar imzalamıştır.

\section{Bulgular ve yorum}

$\mathrm{Bu}$ bölümde, emojilerin tasarlanması ve konseptine ilişkin strateji, yaratıcı strateji ve emoji tasarımlarına yer verilmiştir.

\section{Arka plan araştırması}

Yeni Koronavirüs Hastalı̆̆ı (COVID-19) Çin’in Vuhan Eyaleti’nde Aralık ayının sonlarında solunum yolu belirtileri (ateş, öksürük, nefes darlığı) gelişen bir grup hastada yapılan araştırmalar sonucunda 13 Ocak 2020'de tanımlanan bir virüs olarak ortaya çıkmıştır. Salgın başlangıçta bu bölgedeki deniz ürünleri ve hayvan pazarlarında bulunanlarda tespit edilmiş, daha sonra insandan insana bulaşarak Vuhan başta olmak üzere Hubei eyaletindeki diğer şehirlere ve Çin Halk Cumhuriyeti’nin diğer eyaletlerine ve diğer dünya ülkelerine yayılmıştır.

Salgın her yönüyle tüm dünyayı etkisine alırken, özellikle 10 ülkede yüksek derecede etkileri görüldü. Salgının sağlık üzerinde yarattığı ölümcül etkilerine ek olarak tüm sistemler üzerinde de ağır tahribatları görüldü. İş dünyası, eğitim, sosyal hayat, ekonomik hayatta da yeni çözümler, yeni sistemler geliştirme yönünde bir araç oldu. Bu ortak soruna ortak çözümler bulunurken dünya belki de ilk defa ortak bir iletişim dili kullandı. Bu ortak iletişim dilinde sembollerin özel önemi bulunmaktadır.

\section{Problem}

Beklenmedik bir şekilde insanların günlük hayatlarına giren Covid-19 insanların düşünce ve duygu dünyalarını da etkisi altına aldı. Bu etkinin olumlu ve olumsuz yansımaları oldu. Bunlardan en çok üzerinde durulan bazı duygu-davranış kalıpları şu şekildedir:

Kaygı bozukluğu

Uykusuzluk ya da aşırı uyku hali

Sosyalleşme ihtiyacı

Halsizlik ve hiçbir şey yapmama 
Bilinmeyene karşı aşırı tepki hali

\section{Yöntem ve yaklaşım}

Covid-19'un aynı anda dünyayı etkisi altına alması, ülkelerin ortak karantina dönemleri insanın en temel ihtiyacı olan iletişim ihtiyacını daha da artırmış ve aynı anda tüm dünyada dijital iletişim kanallarına olan ihtiyaç ve kullanım oranı otomatik olarak artmıştır. Bu doğal artış teknik altyapının sunduğu imkanlar, karantina süreçlerinde dışarı ile kesilen fiziki bağlantının doğal sonucu olarak karşımıza çıksa da dijital mecraların sundukları içerikler, bilgi kaynaklarının zenginliği, açık kütüphane ve bilgiye erişim kaynaklarının bolluğu sürecin kazanımları olmuştur. Bu noktadan hareketle Covid-19'un yarattığı bu ortamın bireyler üzerinde yarattığı etkiyi anlatmak üzere konu beş farklı tema ile ele alınmış ve bu temalar altında dünyanın ortak dili haline gelen “emoji” çalışması yapılmıştır.

Bu temalar;

Meslek ve İşyeri

Duygu Tutum Durumu (İnsan/Virüs)

Tedbirler

Ülkeler ve İnsanlar

Evde Kal

\section{Yaratıcı strateji}

Görsel kimlik: Yaratılan emojilerin ortak özelliği dünya genelinde yaşanan ortak soruna verilen ortak tepkileri, düşünceleri, ortak davranış-tutum kalıplarını yansıtıyor olmasıdır. Emojiler, pandemi sürecinde dünyayı algılama biçimimizi renk, tipografi, evrensellik kriterleri gözönüne alınarak çalışılmıştır. Çalışma sırasında üretilen emojiler, sosyal medya mecralarından alışık olduğumuz temel düzeydeki görsellerin, süreç-durum uyarlamaları ile zenginleştirilmiş halidir. Farklı başlıklar için farklı renkler ve ikonlar kullanılsa da bunların tamamı ortak kültüre hitap etmektedir.

\section{Tema 1: Duygu tutum durumu (insan/virüs)}

Dünyaya yayılan Covid-19 virüsünün insanları eve kapatması üzerinden çalışllan emojiler ise "tecrit" "hapis hali" kavramları üzerinden görselleştirilmiştir.

Tasarlanan emojilerde bu süreçte dış dünya ile bağlantımıza dair ipuçları vurgulanmıştır. Sosyal yaşamın kısıtlılığı üzerinden çalışılan emojiler ise insanların nelerden mahrum kaldığına vurgu yapmaktadır. Serilerde evde yapabileceğimiz aktiviteleri, dışarıda yapamadıklarımızı, süreçte insanların yaşadıklarını vurgulayan emoji aileleri de çalışılmıştır.

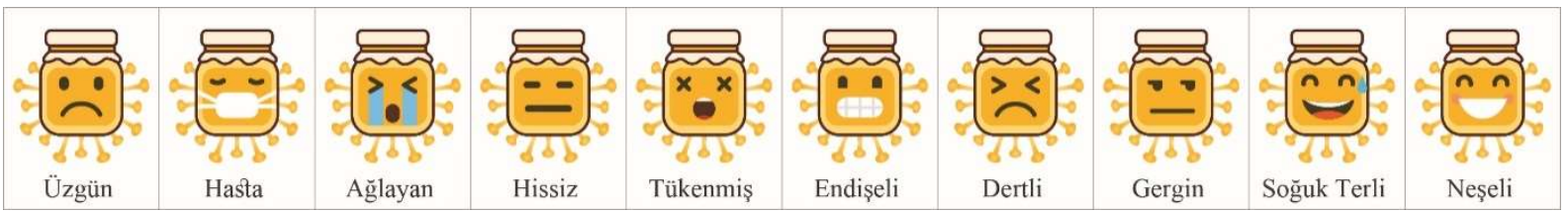

Görsel 1, B.B, Emoji Tasarımı 
"Koronavirüs bu süreçte bana sanki kapalı bir kavanozun içine sıkışmışım gibi hissettirdiği için, emojilerimde kavanoz kulllanmayı tercih edilmiştir. Bu süreçteki değişen ruh halleri emojilere yansitılmıştır."

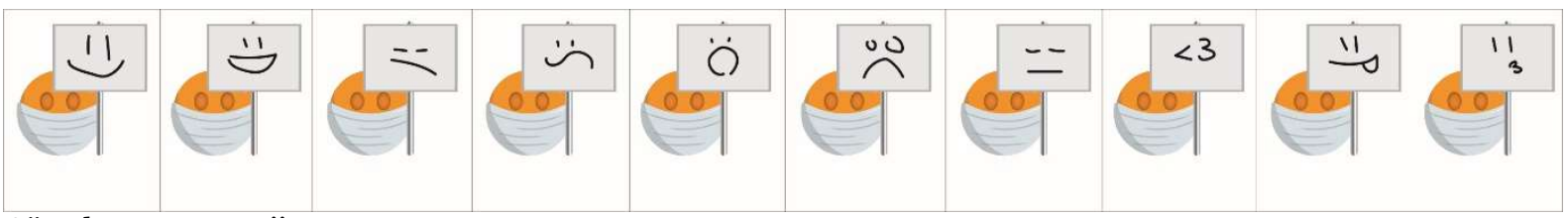

Görsel 2, M.T, Emoji Tasarımı

“COVID-19 yüzünden insanlar yüz maskesi takmak durumunda kaldı, böylelikle yüzleri ve ifadeleri görülememektedir. Sağlıklı kalmayı tercih ettikleri için maskelerini çıkarmadan, tabelalar kullanarak ifadelerini belirten emojiler tasarlanmıştır."
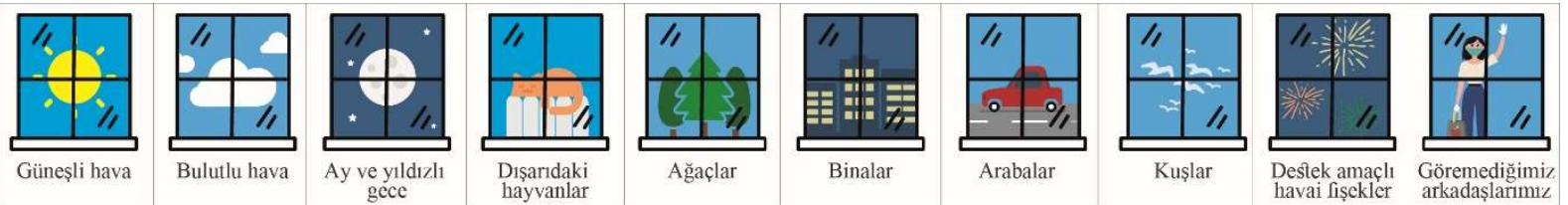

Görsel 3, N.K , Emoji Tasarımı

Dünyaya yayılan COVID 19 virüsünden dolayı insanlar evlerinde karantinada kaldılar. Tasarlanan emojilerde bu süreçte dışarısı ile iletişimin 'nasıl olduğu' vurgulanmak istenmiştir.

\section{Tema2: Tedbirler}

Covid-19 ile mücadele için alınan tedbirler tüm dünyanın ortak tedbirleri oldu. Maske kullanmak, sosyal mesafede kalmak, el hijyeni, dengeli beslenme, düzenli uyku hayatımızın bir parçası oldu. Tedbirler arasında yer alan karantina ise sürecin en zorlayıcı bölümüydü. Süreçte uzak kaldığımız olay, durum, mekan vb. hallerimizi maske üzerinde sembolize eden emojilerin yanı sıra tedbirleri açıkça gösteren yalın emojiler de üretilmiştir.
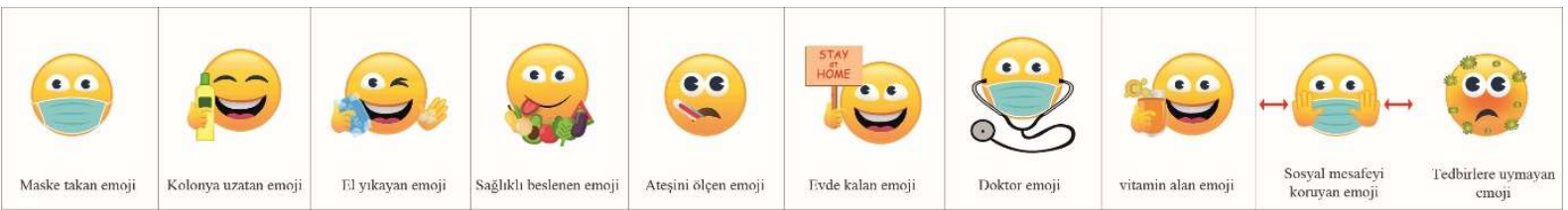

Görsel 4, A.U, Emoji Tasarımı

"Bu emojiyi tasarlarken COVID 19 salgını sürecinde uyulması gereken tedbirlere dikkat çekilmiştir.

Hastalıktan korunma yöntemleri ve zoraki tedbirler emojiler üzerinden gösterilmiştir.”

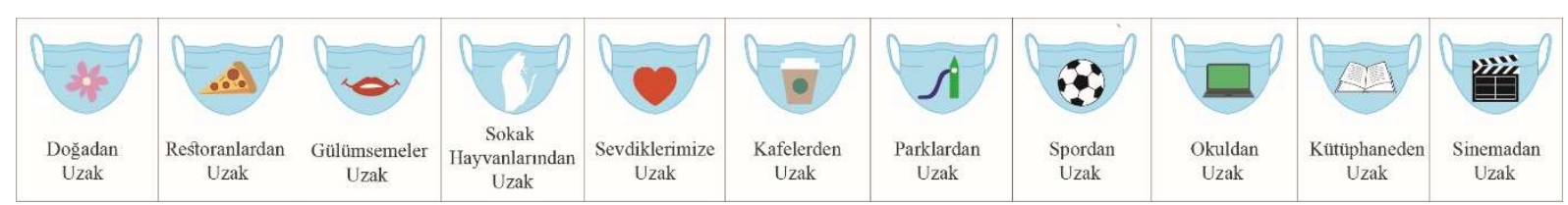

Görsel 5, S.B, Emoji Tasarımı

"Emojiler tasarlanırken maske üzerine uzak kalınan bazı mekanları, hayvanları ve insanları anlatan çizimler yerleştirilerek COVID 19'dan sonra hayatımıza giren uzaklık kavramı gösterilmek istenmiştir.” 


\section{Tema3: Ülkeler ve insanlar}

Covid-19 karşısında dünya ortak hareket etse de ülkelerin yayılan hastalı̆̆a karşı gösterdikleri farklılıklar da oldu. Bu farklılıklar ülkelerin aldıkları önlemler, ülke halklarının dışarıya yansıttıkları duygular üzerinden emojilere aktarılmak istenmiştir.

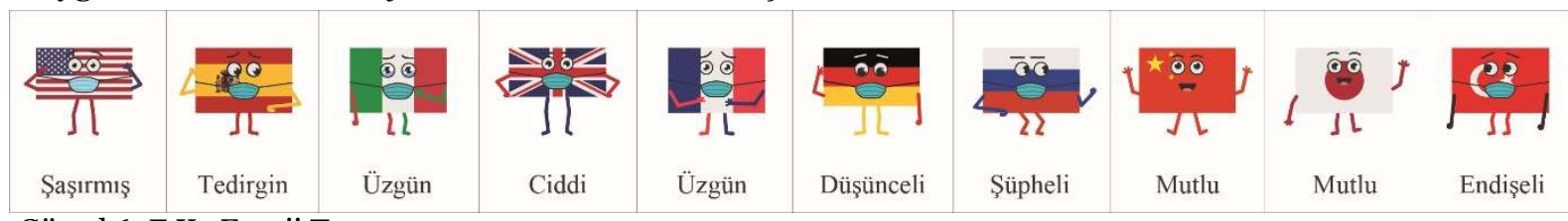

Görsel 6, F.K, Emoji Tasarımı

Dünya genelinde yayllan "COVID-19" pandemisinden etkilenen ülkelerin yayllan hastalı̆̆a karşı duruşları, aldıkları önlemler dikkate alınarak ülke halklarının dışarıya yansıttıkları duygular

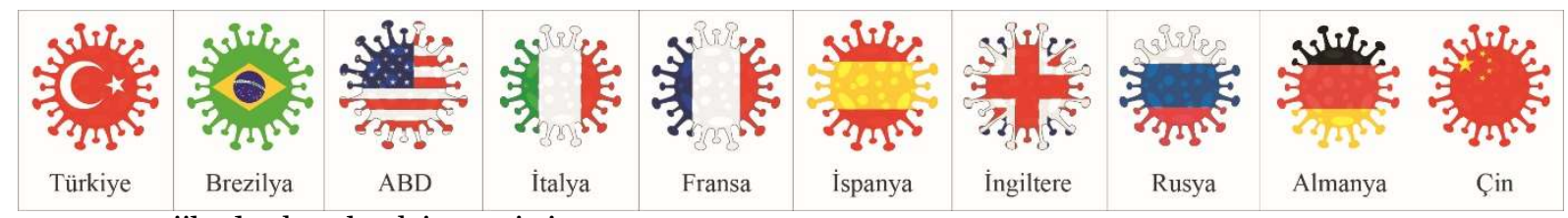

emojilerde aktarılmak istenmiştir.

Görsel 7, Emre Gürün, Emoji Tasarımı

"Dünyayı etkisi altına alan "Koronavirüs” pandemisi uluslararası bir halk sağlığı sorunudur. Her gün binlerce insan, dünyanın dört bir yanında hayatını bu virüs yüzünden kaybediyor. Kimi ülkeler ölüm sayısını azaltmaya çalışıyor, kimi ülkeler vaka sayısını, kimi ülkeler ölümler sonucunda mezar bulmaya çalışıyor, kimi ülkeler çareyi başka ülkelerden yardım istemekte buluyor... Bu tasarımda "Koronavirüs”ün uluslararası boyutuna dikkat çekilmek istendi. Sonuçta, virüsün en çok etkisi altına aldığı 10 ülkeyi temsil eden bayraklar, virüs şekli verilerek mesaj verilmek istendi.”

\section{Tema 4: Evde kal}

Dünyanın ortak sloganı haline gelen "evde kal” çağrısı her sektöre, her kesime yansıtılmıştır. Bazı emojilerde bu çağrıya vurgu yapılmıştır.

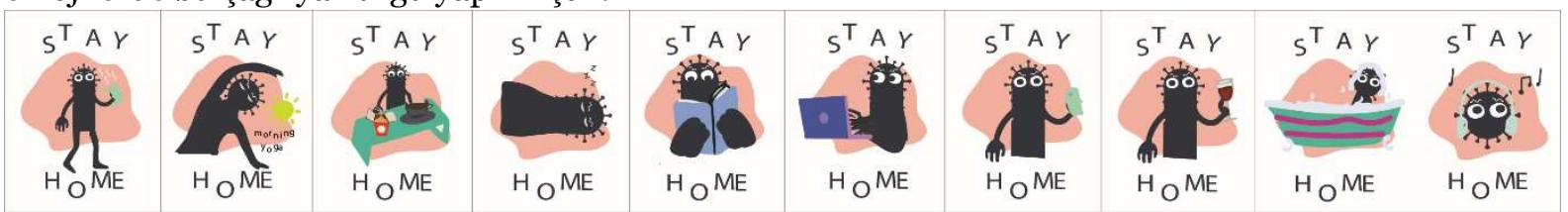

Görsel 8, A.B.T, Emoji Tasarımı

Koronavirüs emoji tasarımları insanların tamamen evde kalmalarına katkı sağlamak için "Stay Home" sloganına uygun bir şekilde tasarlanmıştır. İnsanların bu süreçte evde kaldığında yaptığı aktiviteleri ve etkinlikleri virüs emojisiyle farklı bir şekilde anlatılmak istenmiştir.

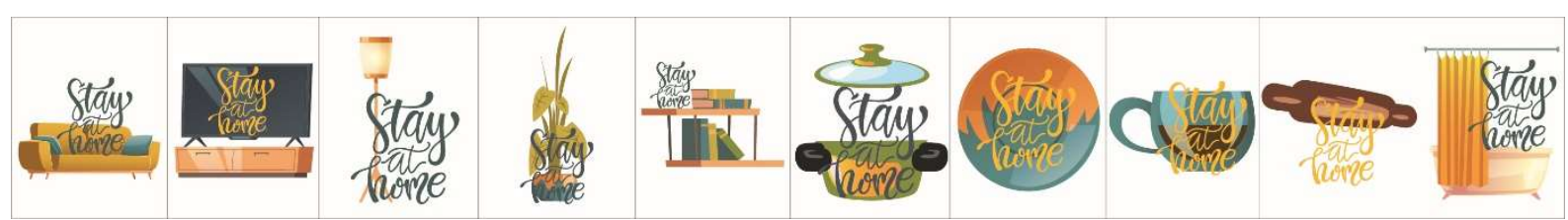

Görsel 9, A.Ş , Emoji Tasarımı 
"Karantina sürecini evde geçiriyoruz. Bu süreçte evden fotoğraflar, tweetler, blog yazıları paylaşıyoruz. Bunun için sosyal medyada tag oluştururken, paylaşım yaparken, tweet atarken, bloğumuzda paylaşacağımız yazının açıklama kısmına ya da mesaj gönderirken kullanabileceğimiz ev eşyalarının emojilerini yaptım. Bu sayede evde kal mesajını daha eğlenceli vermiş olacağız. Yaptığımız işleri de tek bir emoji ile anlatabileceğiz. İngilizce evrensel bir dil olduğu için evde kal mesajını türkçe yazmadım, böylece kullandığımız herhangi bir mecrada kolayca anlaşılabilecek."

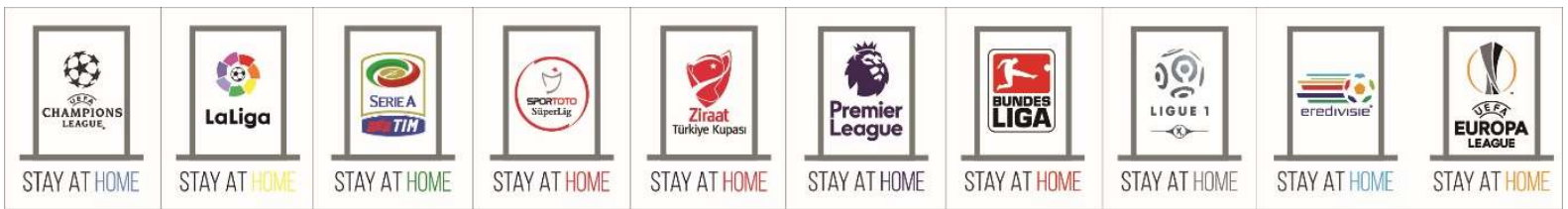

Görsel 10, M.T.M., Emoji Tasarımı

"Bu emojiler ile Covid-19 virüsünün tüm dünya üzerinde olușturduğu olumsuz etkinin sosyal yaşantının belkide en önemlilerinden olan futbol sporunun da olumsuz etkileri gösterilmek istenmiştir."

\section{Meslek ve işyeri}

Bu grupta çalışılan emojiler, virüsten en çok etkilenen çalışma alanları baz alınarak yapılmıştır. Covid19'un en çok etkilediği çalışma alanları seçilmiş durumun hem ulusal hem de uluslararası boyutuna dikkat çekilmiştir.
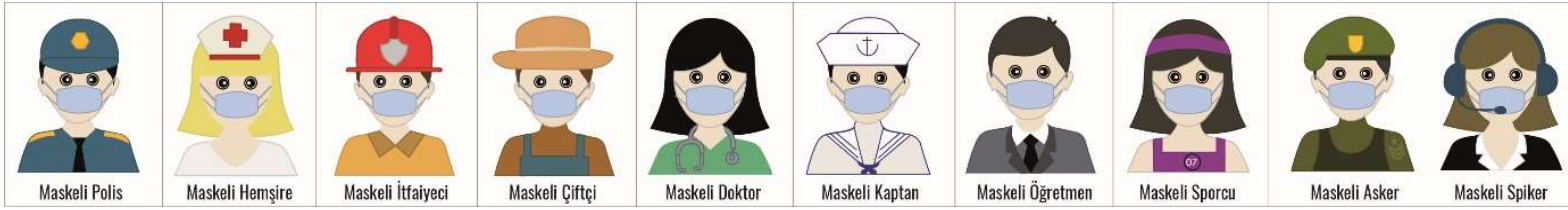

Görsel 11, C.G, Emoji Tasarımı

"Bu emojiler hayatımızın her yerine engel olan COVID 19'dan etkilenen meslek dallarına dikkat çekmek amacı ile tasarlanmıştır.”

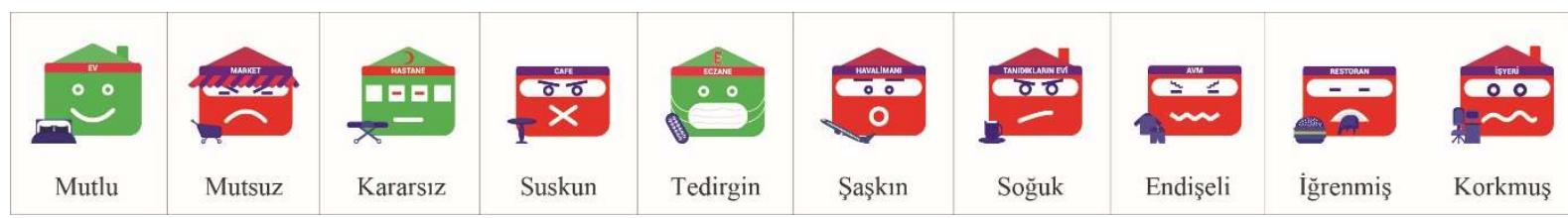

Görsel 12, S.A, Emoji Tasarımı

"Bu emoji tasarlanırken Covid-19 için güvenli ve tehlikeli alanlar ele alınmıștır. "Emojiler, insanların bu zor dönemlerinde mekanlar hakkında düşündükleri veya hissettikleri göz önüne alınarak tasarlanmıştır."

\section{Sonuç}

Sözsüz iletişim, iletişimin temel yapı taşlarından biridir. Günlük yaşamda kişilerarası ilişkilerde kullanılan simgesel kodlar içinde sözsüz olanlar anlam yaratma ve paylaşmada çoğu kez bilincinde olmaksızın ancak sürekli olarak kullanılırlar. Yaşadığımız çağın en önemli ve en çok kullanılan araçlarından biri olan internet bireylerin iletişimde kullandıkları en önemli medyalardan biri haline gelmiştir. Bu teknoloji ile birlikte bireylerin bilgiye hızlı ve kolayca ulaşabilmeleri bu hıza uyum sağlayabilmek için bu konuyla ilgili çeşitli çözümler bulmalarına neden olmuştur. Bu hızlı iletişime yardımcı olan ikonlardan biri de emojilerdir. Duygularını ifade etme ihtiyaçlarını gidermek amacı ile tasarlanan emojiler, gündelik hayatın vazgeçilmezi haline gelmiştir. 
Covid19 ise son verilere göre dünyada çok fazla insana bulaşmış oldukça tehlikeli ölümcül bir virüstür. $\mathrm{Bu}$ virüs için alınan önlemlerin başında sosyal izolasyon ve evde kalmak gelmektedir. Birçok ülke vatandaşlarına evde kalma çağrısı yapmış ve zaman zaman sokağa çıkma kısıtlamaları ile bu durumu desteklemişlerdir. Bu durum toplumsal, ekonomik ve psikolojik bir çok alanı ve insanı etkilemiştir.

Bu doğrultuda, bu çalışma ile öncelikle insanlarda hastalıkla ilgili bilinç oluşturmak istenmiş ve 7 temada (Duygu durumu, Tedbirler, Ülkeler ve insanlar, Evde kal, Meslek ve işyeri) insanları etkileyen psikolojik, ekonomik ve toplumsal sonuçlar verilmeye çalışılmıştır. Ayrıca, emojilerle evrensel ortak bir dil oluşturmak ve kısa sürede çok sayıda kişiye ulaşmak hedeflenmiştir.

$\mathrm{Bu}$ çalışmadan çıkarılacak en önemli sonuç insanların tasarlanan emojiler ile iletişime geçebilmeleri ve virüs konusunda bilinçlenmelerini sağlamaktır.

Bireylerin yaşadıkları bu pandemi sürecini daha bilinçli atlatabilmeleri için sözsüz iletişim dili olan emojiler konusunda farkındalık oluşturacak daha fazla çalışma yapılmalıdır.

\section{Kaynakça}

Ayan A. \& Kıraç S. “COVID-19 Pandemisi Sürecinde Nükleer Tip Uygulamaları İçin Kılavuz”, Sağlık Bilimleri Üniversitesi, Ankara, 2020

Boothe D., Wickstrom C. (2017). Esol learners must confront diverging language pathways between social media and english for specific purposes, in Paper Presented at the 1oth International Conference of Education, Research and Innovation (Beijing: ).

Cheng L. (2017). Do I mean what I say and say what I mean? A cross cultural ap-proach to the use of emoticons \& emojis in CMC messages. Fonseca J. Commun. 15, 199-217.

Cho K.-L. (2016). The Differences Of Emoticon Use And İts Effects Depending Upon Problem Types And Discussion Message Types İn The Process Of Online Problem-Solving Discussions. J. Educ. Technol. 32, 355-390.

Çeken, B., Arslan, A. A. ve Tuğrul, D. (2017). İletişimde Emojilerin Kullanımı ve İncelenmesi. 21. Yüzyılda Eğitim ve Toplum, 6 (16), Bahar 2017.

Davis, M., \& Edberg, P. (2016). Unicode Emoji. Retrieved from http://unicode.org/reports/tr51/

Dikmen A. , Kına H. , Özkan S. , İlhan M. “COVID-19 Epidemiyolojisi: Pandemiden Ne Ögrendik”, Gazi Üniversitesi Tıp Fakültesi Halk Saglıgı Anabilim Dalı, Ankara, 2020

Dimson T. (2015). Emojineering part 1: machine learning for emoji trends. Instagr. Eng. Blog 30.

Dimson, T. (2015), “Emojineering Part 1: Machine Learning for Emoji Trends”,

Dresner E., Herring S. C. (2010). Functions of The Nonverbal In CMC: Emoticons And İllocutionary Force. Commun. Theory 20, 249-268.

Demiray, K., Çeviker A. (2020). Covid - 19 Aşı ve Toplumsal Korunma. Journal of Biotechnology and Strategic Health Research, 1(Özel Sayı):37-44.

Ganster T., Eimler S. C., Krämer N. C. (2012). Same same but different!? The differential influence of smilies and emoticons on person perception. Cyberpsychol. Behav. Soc. Netw. 15, 226-230.

Gürgen, H. (1997). Örgütlerde İletişim Kalitesi. İstanbul: Der Yayınları.

Hjartstrom H., Sorman D. E., Ljungberg J. K. (2019). Distraction and facilitation: the impact of emotional sounds in an emoji oddball task. PsyCh J. 8, 180-186.

Instagram Engineering Blog, https: //instagram-engineering.com/emojineering-part-1-

Jaeger S. R., Ares G. (2017). Dominant meanings of facial emoji: insights from Chinese consumers and comparison with meanings from internet resources. Food Qual. Prefer. 62, 275-283. 
Jaeger S. R., Roigard C. M., Jin D., Vidal L., Ares G. (2019). Valence, arousal and sentiment meanings of 33 facial emoji: insights for the use of emoji in consumer research. Food Res. Int. 119, 895907.

Kaya, T. (2017). “Yeni Medyada Emoji Kullanımının Anlamı”, Akademik Bakış Dergisi, 60, 567-584.

Kaye L. K., Wall H. J., Malone S. A. (2016). Turn that frown upside-down: a contextual account of emoticon usage on different virtual platforms. Comput. Hum. Behav. 6o, 463-467.

Lim S. S. (2015). On Stickers and Communicative Fluidity In Social Media. Social. Media+Society 1, 13 .

Lo, S. K. (2008). The Nonverbal Communication Functions Of Emoticons İn Computer-Mediated Communication. Cyberpsychology \& Behavior, 11(5), 595-597. machine-learning-for-emojitrendsmachine-learning-for-emoji-trends-7f5f9cb979ad.

Na'aman N., Provenza H., Montoya O. (2017). Varying linguistic purposes of emoji in (twitter) context, in Paper Presented at the ACL 2017, Student Research Workshop.

Özdemir Ö. \& Pala A. “Çocuklarda COVID-19 Enfeksiyonunun Tanısı, Tedavisi ve Korunma Yolları”, Sakarya Üniversitesi Tip Fakültesi, 2020

Prada M., Rodrigues D. L., Garrido M. V., Lopes D., Cavalheiro B., Gaspar R. (2018). Motives, Frequency And Attitudes Toward Emoji And Emoticon Use. Telematics Inform. 35, 1925-1934.

Prada M., Rodrigues D. L., Garrido M. V., Lopes D., Cavalheiro B., Gaspar R. (2018). Motives, frequency and attitudes toward emoji and emoticon use. Telematics Inform. 35, 1925-1934.

Sakai N. (2013). The Role Of Sentence Closing As An Emotional Marker: A Case Of Japanese Mobile Phone E-Mail. Discourse Context Media 2, 149-155. 10.1016/j.dcm.2013.07.001.

Sampietro A. (2019). Emoji and rapport management in Spanish WhatsApp chats. J. Pragmat. 143, 109-120.

Sodikin M. (2018). Emoticon Symbols Applied For Traffic Signs, International Conference on Applied Science and Engineering (ICASE 2018).

Stark L., Crawford K. (2015). The conservatism of emoji: work, affect, and communication. Social Media+ Society 1, 1-11. 10.1177/2056305115604853

Tavşancıl, E., \& Aslan, E. (2001). İçerik Analizi Ve Uygulama Örnekleri. Epsilon Yayınları: İstanbul.

Til A. (2020) "Yeni Koronavirüs Hastalığı (covid-19) Hakkında Bilinmesi Gerekenler" Göller Bölgesi Ayllk Ekonomi ve Kültür Dergisi, 2020;8

Torun, B. U. (2018). Z Kuşağının akıllı telefonlar üzerinden yazıl iletişimde emoji kullanma eğilimlerine yönelik bir araştırma. TRT akademi Ekran Kültürü 3 (6), 614-631.

Vanin A. A., Freitas L. A., Vieira R., Bochernitsan M. (2013). Some clues on irony detection in tweets in Paper Presented at the 22nd International Conference on World Wide Web.

Wang S. S. (2016). More than words? The effect of line character sticker use on intimacy in the mobile communication environment. Soc. Sci Comput. Rev. 34, 456-478.

Zllloglu, M. (1996 ). İletişim Nedir? İstanbul: Cem Yayınları.

(http://www.tdk.gov.tr/).

(https://covid19bilgi.saglik.gov.tr/ 